\title{
EXPRESSÃO DE ATITUDES NA FALA COM GAGUEIRA: PERCEPÇÃO DE FALANTES FLUENTES
}

\author{
Leticia Correa CELESTE* \\ César REIS**
}

- RESUMO: O objetivo deste estudo foi verificar como falantes fluentes do português brasileiro percebem a expressão das atitudes de certeza e dúvida em falantes com gagueira. Para tanto, foram coletados dados em dois momentos: 1. material de fala e 2. teste perceptivo. Dois grupos participaram do primeiro momento, sendo 12 indivíduos com gagueira (GE) e 12 sem (GC). Esses participantes gravaram 2 frases em cada uma das três formas estudadas (neutra, expressão de dúvida e expressão de certeza). Para teste perceptivo participaram 60 juízes: 30 julgaram os enunciados do GC e 30 julgaram os enunciados do GE. Foram contabilizadas 1440 respostas para o GC e 1080 respostas para o GE. Foi utilizado o teste de uma afirmativa sobre uma e duas proporções, com significância de 95\%. Os resultados mostraram diferença estatisticamente significativa entre os resultados dos juízes do GC e os juízes do GE: os juízes reconhecem melhor as atitudes expressas pelas pessoas sem gagueira do que aquelas expressas pelas pessoas com gagueira.

- PALAVRAS-CHAVE: Teste perceptivo. Prosódia. Atitudes. Gagueira.

\section{Introdução}

Sabe-se que a estrutura sonora da comunicação humana pode ser dividida em aspectos segmentais e não segmentais. Dentre os aspectos não segmentais, a prosódia se destaca por ser um instrumento do locutor para a expressão de atitudes, que é o tema da presente pesquisa.

As atitudes são controladas voluntariamente pelo locutor de forma intencional (WILSON; WHARTON, 2006), dentre as quais podemos citar a certeza, a dúvida e a ironia. Uma das formas de analisar teoricamente a função prosódica de expressão de atitudes sob o ponto de vista do ouvinte é por meio das ideias da Teoria da Relevância, a qual foi proposta por Sperber eWilson (1995) e teve como pressuposto teórico a abordagem de Grice para o significado e a comunicação. Iniciaremos, então, esta seção discursando brevemente sobre a proposta de Grice e, em seguida, sobre a Teoria da Relevância em si.

\footnotetext{
* UnB - Universidade de Brasília. Brasília - DF - Brasil. 70.910-900 - leticiaceleste@unb.br

** UFMG - Universidade Federal de Minas Gerais. Faculdade de Letras. Belo Horizonte - MG - Brasil. 31.270901 - creisufmg@gmail.com
} 
Grice descreve a comunicação em termos de intenções e inferências enfocando sempre a relação entre locutores e ouvintes. Como falantes, levamos o nosso ouvinte a reconhecer nossa intenção de informá-lo de alguns estados mentais. Como ouvintes, tentamos reconhecer o que o falante tem a intenção de nos informar (SPERBER; WILSON, 1995). A comunicação envolve a publicação e a compreensão de intenções, já que para Grice significar qualquer coisa a qualquer pessoa consiste em realizar uma relação intencional (SPERBER; WILSON, 1995; PAVEAU; SARFATI, 2006). Sperber eWilson, a partir de questionamentos da teoria proposta por Grice, desenvolvem a Teoria da Relevância, com a primeira edição do livro Relevance \& Cognition em 1986, e a segunda em 1995. Essa teoria tem como base dois princípios gerais, o cognitivo e o comunicativo. O princípio cognitivo é de que a cognição humana tende a ir em direção à maximização da relevância. $\mathrm{O}$ princípio comunicativo refere-se ao fato de que as elocuções geram expectativas de relevância. Esses princípios gerais relacionam-se com o próprio conceito de relevância, que é tida como uma propriedade das entradas de dados para os processos cognitivos (sejam eles elocuções, memória, sons, etc.). Mas o que torna uma entrada de dados relevante ou não? Para que uma entrada de dados seja relevante ela tem que "valer a pena ser processada" e isto é explicado em termos de efeito cognitivo e de esforço de processamento (SPERBER; WILSON, 1995).

Para Sperber e Wilson, os efeitos cognitivos são o fortalecimento e a contradição das suposições existentes, bem como a combinação entre elas resultando em implicações contextuais. Dessa forma, quanto maior são os efeitos cognitivos, maior é a relevância. Por outro lado, para que esses efeitos cognitivos sejam processados, o ouvinte deve realizar algum esforço mental, e quanto menor for este maior é a relevância.

Para interpretação de uma elocução, o ouvinte deve satisfazer sua expectativa de relevância, como sugere o princípio comunicativo da relevância. Devem ser processadas, então, as informações explícitas e implícitas de forma a considerar as hipóteses interpretativas (desambiguações, suposições, etc.) e interromper o processamento assim que suas expectativas alcançarem o nível esperado de relevância (SPERBER; WILSON, 1995).

Dessa forma, o que está explícito não se limita a "descodificação", e sim abrange um elemento inferencial. Para Sperber eWilson isso traz como implicações um estreitamento ou alargamento do sentido literal. Dentro da visão de alargamento do sentido literal, vejamos o exemplo dado pelos autores (SPERBER; WILSON, 1995, p.239):

(1) a. Ele: Está um lindo dia para um piquenique.

[Eles partem para um piquenique e o sol brilha]

b. Ela (alegremente): Está, na verdade, um lindo dia para um piquenique. 
(b) a. Ele: Está um lindo dia para um piquenique.

b. Ela (sarcasticamente): Está, na verdade, um lindo dia para um piquenique.

Em (1), pode-se analisar que as elocuções proferidas tiveram o sentido literal e estreito utilizados pelos falantes. Já em (2), a atitude "sarcasmo" utilizada em b é manifestada, ou expressa, por meio de aspectos prosódicos. Esses são considerados importantes para os autores, porém os mesmos não entram em detalhes de como o interlocutor, no caso (2) a, percebe a fala como sarcástica. Sabe-se que o contexto auxilia em tal interpretação, mas acreditamos que exista algo a mais, que seria justamente os aspectos prosódicos da fala.

No entanto, sabe-se que indivíduos com desordens de fala, como a gagueira, podem ter dificuldades de se expressar. A gagueira é um distúrbio da comunicação humana que afeta diretamente a fluência da fala, causando interrupções na cadeia segmental devido a erros na programação motora temporal, com sucessivas tentativas de retomada da fluência.

Dessa forma, os indivíduos com gagueira apresentam um prejuízo considerável na produção da fala tanto na cadeia segmental (CAMPBELL; HILL, 1995; ANDRADE, 1999) quanto na prosódia (BOSSHARDT et al., 1997; SOARES, 2004; ARCURI et al., 2006; CARDOSO; REIS, 2008; ARCURI et al., 2009). Como consequência, espera-se que a fala desses indivíduos apresente limitações na expressão de atitudes, sendo esta uma função prosódica.

Perguntamo-nos, então, como pessoas com gagueira são percebidas por falantes fluentes na expressão das atitudes? Com base em tal questionamento, levantamos uma hipótese. Antes de expô-la, é necessário que partamos de um pressuposto básico sobre a expressão de atitudes. Os locutores deste estudo foram todos previamente instruídos a produzir enunciados ora neutros, ora expressando atitudes. Dessa forma, consideramos que os locutores, nos momentos nos quais foram instruídos a expressar atitudes, tiveram a intenção de produzi-las. Ou seja, todos os participantes, com gagueira ou não, tiveram a intenção de expressar certeza e dúvida. Acreditamos, no entanto, que apesar de todos assumirem a mesma posição inicial de intenção de expressão de atitude, os indivíduos que não apresentam gagueira apresentarão maior sucesso, ou seja, um número maior de interlocutores perceberá tais atitudes.

\section{Métodos}

Para realização desta pesquisa, dois momentos distintos de coleta de dados foram realizados, duas etapas: gravação do material de fala e teste perceptivo. Os participantes do primeiro momento não participaram do segundo. 


\section{Primeira etapa: gravação do material de fala}

Participaram da primeira etapa 24 indivíduos, com idades entre 20 e 40 anos, nascidos e criados na região metropolitana de Belo Horizonte, separados em dois grupos.

O primeiro grupo, experimental, foi composto por 12 indivíduos do sexo masculino diagnosticados com gagueira do desenvolvimento. Para determinar o grau de severidade da gagueira dos participantes foi utilizada escala cuja pontuação divide-se em quatro componentes (YAIRI; AMBROSE, 1999; JAKUBOVICZ, 1997): frequência e duração das disfluências, tensão e fenômenos secundários. Para esta pesquisa foram selecionados participantes entre os graus 5 a 7 da escala de severidade de Iowa (numa escala de 1, ausência de gagueira, à 7, gagueira grave) por corresponderem aos níveis moderado e grave, já que o objetivo deste estudo é observar o fenômeno das disfluências gagas na expressão de atitudes. Nenhum dos participantes do grupo experimental passou por qualquer tipo prévio de tratamento para melhora da fluência. Todos tinham escolaridade entre ensino médio completo e ensino superior incompleto. O grupo experimental foi dividido em dois subgrupos: os participantes com gagueira moderada (grau 5) e aqueles com gagueira grave (grau 7).

O segundo grupo, grupo controle, foi composto por 12 indivíduos fluentes. Estes foram pareados com o grupo experimental quanto ao sexo, idade e escolaridade. Os participantes do segundo grupo não poderiam apresentar gagueira. Os critérios escolhidos para separação dos grupos com e sem gagueira foram: 1. Queixa do próprio participante, 2. Análise do perfil de fluência da fala, segundo a proposta de Martins e Andrade (2008).

Dessa forma, contamos com três grupos, a saber:

- Grupo experimental 1 (GE1): oito indivíduos com gagueira moderada;

- Grupo experimental 2 (GE2): quatro indivíduos com gagueira severa;

- Grupo controle (GC): 12 indivíduos sem gagueira.

O corpus de gravação do material de fala foi composto de duas frases: 1. ele volta a jogar e 2 . ele conhece as regras. Ambas as frases foram gravadas de forma neutra (leitura), expressando certeza e expressando dúvida (por todos os participantes). Ao realizar as gravações do GC, observamos que ora eles produziam dúvida com uma forma mais próxima da modalidade declarativa, ora mais similar à modalidade interrogativa. Por esse motivo, optamos por gravar duas formas neutras no GC: leitura das frases na forma declarativa e leitura das frases na forma interrogativa. Tal fato resultou em uma diferença no número final da amostra do teste perceptivo. 


\section{Segunda etapa: o teste perceptivo}

Para elaboração e análise do teste perceptivo, é necessário retomar a hipótese inicial de que os indivíduos que não apresentam gagueira apresentarão maior sucesso. Ou seja, o objetivo do teste perceptivo desta pesquisa não é realizar etiquetagem prévia das atitudes que serão analisadas. A finalidade é verificar qual o índice de sucesso na produção dos falantes. Isto significa que, a partir da produção total dos indivíduos, verificamos qual a proporção de reconhecimento da atitude por interlocutores.

Tal abordagem foi escolhida por acreditarmos que a partir de uma mesma intenção comunicativa os participantes podem se expressar utilizando os parâmetros prosódicos de diferentes formas, tendo como resultado diferentes índices de relevância para os interlocutores. Como temos a hipótese de que alguns parâmetros prosódicos podem estar alterados na fala de indivíduos com gagueira, os resultados do teste perceptivo revelarão um pior desempenho.

Participaram do teste perceptivo 60 indivíduos pareados com o GE: sexo masculino, faixa etária entre 20 e 40 anos, com ensino superior incompleto ou completo e sem queixas de alterações de fala ou audição. A diferença é que nenhum dos participantes do teste perceptivo apresentava gagueira, assim como o GC. Esses participantes foram divididos em dois grupos: um grupo $(n=30)$ escutou somente os dados do GC e o outro grupo ( $n=30)$ escutou somente os dados do GE.

Da gravação de fala, tínhamos 48 enunciados para o GC (incluindo enunciados declarativos, interrogativos, com expressão de certeza e com expressão de dúvida) e 36 enunciados para o GE (incluindo enunciados declarativos, com expressão de certeza e dúvida).

Dessa forma, o corpus para o teste perceptivo foi de 84 enunciados divididos em dois grupos (GC e GE). Esses dados foram organizados da seguinte forma: uma pasta contendo os enunciados do GC, e outra contendo os enunciados do GE. Tanto para os participantes que ouviram os dados do GC quanto para os participantes que ouviram os dados do GE, a ordem de apresentação dos enunciados foi aleatória e randomizada. Os procedimentos para a coleta dos dados do teste perceptivo foram os mesmos para os dois grupos e seguiram os passos a seguir.

Cada participante recebeu uma folha de papel contendo as instruções para realização do teste, seguidas da ilustração de uma escala e, por fim, do quadro para marcação. Abaixo, uma ilustração com as instruções, a escala e a primeira linha do quadro. 


\section{Figura 1 - Recorte da folha de marcação do teste perceptivo.}

Nesta folha você tem uma escala que vai de $-3 a+3$ representando uma gradação na expressão de dúvida e certeza que passa pelo neutro que é igual a 0 .

No quadro logo abaixo, estão indicadas as diferentes frases que você vai ouvir que estão acompanhadas da escala mencionada acima.

Você vai ouvir 30 frases. Cada frase será tocada 3 vezes. Depois de ouvir a frase, marque qual pontuação que você considera mais adequada. Você tem alguma pergunta?

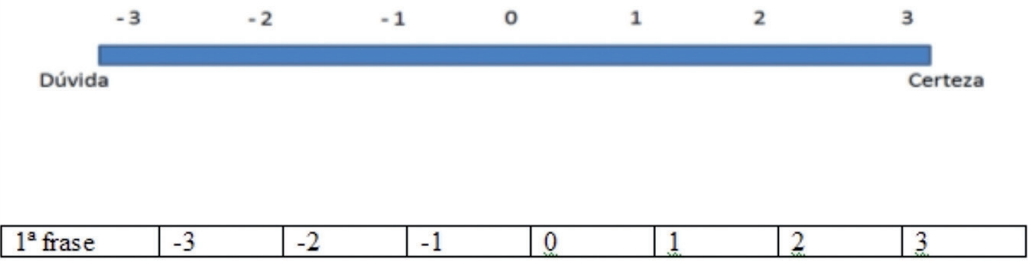

Fonte: Elaboração própria.

Após lerem a folha de resposta e tirarem as dúvidas (quando ocorriam), dava-se início ao teste. Cada enunciado era tocado três vezes e os participantes marcavam na linha da frase que ouviam o número que achavam mais apropriado. Ressalta-se, entretanto, que apesar de terem sido apresentadas três vezes cada enunciado, o participante do teste perceptivo assinalou apenas uma resposta para cada sentença apresentada.

Aplicamos inicialmente para 66 participantes, mas seis foram excluídos da amostra final por marcarem incorretamente a folha de resposta do teste perceptivo. Os problemas encontrados com esses seis participantes foram:

- Não entendimento das instruções: durante a aplicação a pesquisadora verificou que um participante estava marcando apenas " +3 ". O participante afirmou que entendeu que deveria marcar " +3 " quando ele mesmo tivesse certeza da frase que estava sendo dita.

- Marcação incorreta das linhas: cinco participantes marcaram mais de um número por linha e/ou faltaram linhas a ser preenchidas.

Para análise dos resultados, foram contados para cada tipo de enunciado estudado quantos participantes marcaram um determinado número da escala. Como foram 30 participantes por grupo e cada folha de resposta possibilita a marcação de um mesmo tipo de enunciado 12 vezes, foram contabilizadas 
360 respostas para cada tipo de enunciado estudado por grupo. Assim, foram contabilizadas $\mathbf{1 4 4 0}$ respostas para GC (360 declarativas, 360 interrogativas, 360 expressando certeza e 360 expressando dúvida) e $\mathbf{1 0 8 0}$ respostas para o GE, sendo o último dividido em GE1 (120 declarativas, 120 expressando certeza e 120 expressando dúvida) e GE2 (240 declarativas, 240 expressando certeza e 240 expressando dúvida). A diferença do número final para GE1 e GE2 se deu devido ao número de participantes de cada grupo, culminando numa amostra de fala menor para GE1.

\section{Análise estatística}

A análise do teste perceptivo foi dividida em dois momentos principais: a análise dentro de cada grupo (GC, GE1 e GE2) e a análise entre os grupos. A análise dentro de cada grupo foi realizada por meio da tabulação dos resultados encontrados na escala (de $-3 \mathrm{a}+3$ ) para cada atitude. Foi realizado um teste de proporção para cada atitude (certeza e dúvida separadamente) dentro de cada grupo. Foi utilizado o teste de uma afirmativa sobre uma proporção, testada por meio do uso de uma distribuição normal como uma aproximação para distribuição binomial (TRIOLA, 2005). O índice de confiança utilizado foi de 95\%, com a hipótese de que o esperado era maior do que o não esperado. Vamos detalhar o que isso significa.

A tabulação dos dados seguiu a seguinte proposta: para cada atitude, tínhamos dois números da escala que esperávamos que os participantes do teste perceptivo marcassem. Para expressão de certeza, esperávamos encontrar as respostas +2 e +3 , enquanto para expressão de dúvida esperávamos encontrar -2 e -3. Foram somadas, então, as respostas que esperávamos encontrar, ou seja (+/-) 2 e 3, e somamos as que não esperávamos encontrar (os outros 5 números da escala). No quadro 1 exemplificamos a tabulação: a parte sombreada era a que esperávamos encontrar para atitude de certeza, enquanto a parte sem sombreado era a que não esperávamos.

\section{Quadro 1 - Exemplo de tabulação para análise estatística do teste perceptivo para a fala de pessoas sem gagueira.}

\begin{tabular}{|c|c|c|c|c|c|c|c|c|c|c|}
\hline & -3 & -2 & -1 & 0 & 1 & 2 & 3 & Total & $\begin{array}{c}\text { Total } \\
\text { esperado }\end{array}$ & $\begin{array}{c}\text { Total não } \\
\text { esperado }\end{array}$ \\
\hline Certeza & 0 & 0 & 6 & 60 & 36 & 126 & 132 & 360 & 258 & 102 \\
\hline
\end{tabular}

Fonte: Elaboração própria. 
Comparamos, então, a soma dos dois quadros sombreados, uma vez que esperávamos que na expressão de certeza os ouvintes interpretariam os enunciados com os dois números mais altos da escala, com a soma dos outros cinco quadros não sombreados. Assim, para alcançar o índice de significância de $95 \%$, os valores sombreados deveriam ser maiores do que os não sombreados, e não apenas diferentes, ou seja, as respostas esperadas devem ser obrigatoriamente maiores que as não esperadas para que seja considerado estatisticamente relevante.

Ainda dentro de um mesmo grupo, observamos que as respostas do GE das atitudes de certeza e dúvida estavam muito próximas (ver gráficos 2 e 3, nos resultados). Comparamos então, utilizando o mesmo teste, cada ponto da escala (de -3 a 3) para GE 1 e GE2 comparando as atitudes, também com índice de significância de 95\%, a fim de verificar se as respostas apresentavam diferenças estatisticamente significativas.

Para a análise entre os grupos, realizamos três comparações com a variável grupo: GC X GE1, GC X GE2 e GE1 X GE2. Fizemos cada cruzamento de dados da variável grupo comparando ora os resultados para certeza, ora para dúvida. Estabelecida a variável e o cruzamento dos dados, foi aplicado o teste de uma afirmativa sobre duas proporções (TRIOLA, 2005), sob duas perspectivas.

Na primeira, utilizamos a tabulação proposta para comparação entre os resultados esperados e não esperados para cada atitude. Dessa forma, comparamos os grupos considerando cada atitude e os resultados esperados para essa atitude. A segunda perspectiva foi a análise estatística de comparação de duas proporções de cada ponto da escala (de -3 a +3 ).

\section{Resultados e discussão}

\section{Respostas do teste perceptivo para o GC}

As 1440 respostas encontradas para o GC foram contabilizadas e transformadas em porcentagem. O gráfico 1 apresenta as respostas, em porcentagem, considerando a escala de marcação de -3 a +3 . É importante apontar, neste momento, que os falantes do GC apresentaram duas formas distintas de expressar a dúvida: uma que se assemelha à modalidade declarativa, que chamamos de dúvida 1 , e outra que se assemelha à modalidade interrogativa, denominada dúvida 2. Como as formas eram muito distintas, optou-se por fazer o teste perceptivo das duas formas separadamente. Ressalta-se que tal resultado não foi verificado no grupo GE. 
Gráfico 1 - Resultado em porcentagem do teste perceptivo para o GC.

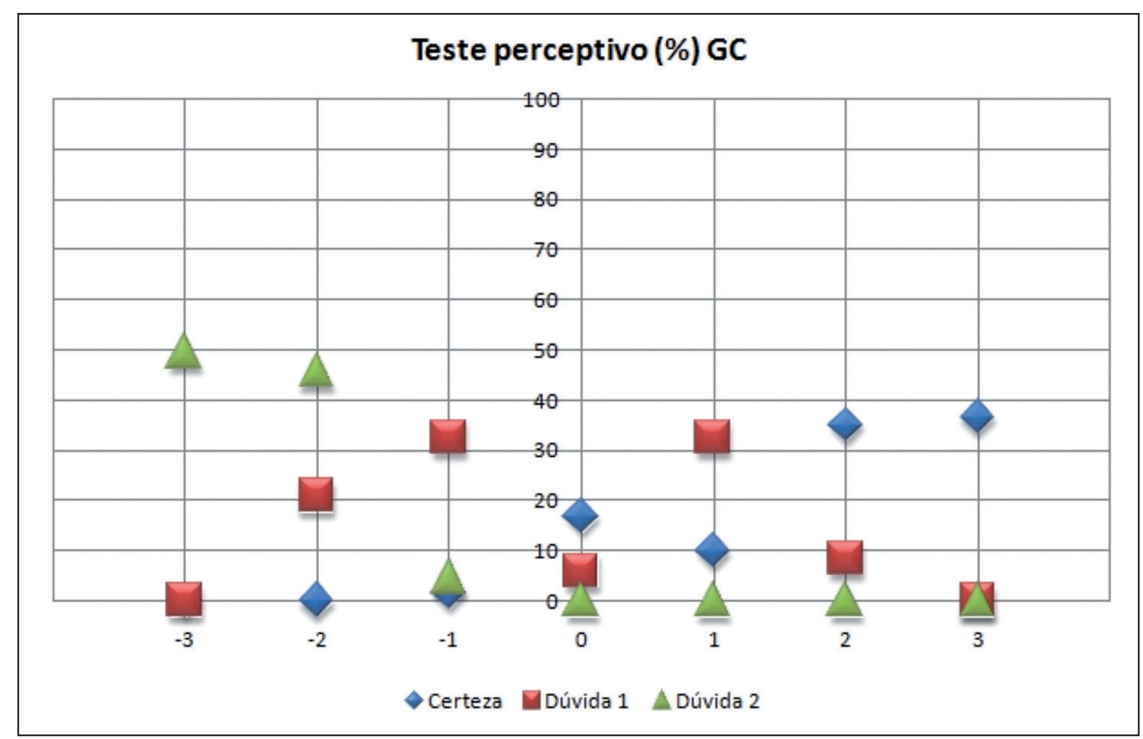

Fonte: Elaboração própria.

Para discussão dos resultados deste teste perceptivo propomos dois tipos de análise do gráfico acima: uma visão pelos quadrantes dos pontos da escala e uma visão de cada atitude. Tendo em vista os pontos da escala, é possível verificar que o zero, ponto representando a neutralidade total do enunciado, recebeu o menor número de respostas comparativamente, ou seja, somando-se todas as respostas (certeza + dúvida 1 + dúvida 2), uma menor porcentagem ficou no ponto zero (8\%). Tal fato indica que, a partir dos dados analisados neste estudo, verificou-se que os juízes consideraram que os enunciados, em geral, expressavam alguma atitude. Na ordem crescente de quantidade de respostas, temos: 0 (8\%); 3 (12\%); -1 (13\%); 1 e 2 (14\% cada); -3 (17\%) e -2 (22\%).

Ao analisarmos as respostas para as atitudes de certeza e dúvida 2, temos um resultado espelhado: nenhuma resposta nos números positivos para a expressão de dúvida 2 e praticamente nenhuma resposta nos números negativos para a expressão de certeza. Assim, todas as respostas para dúvida 2 foram assinaladas nos pontos negativos da escala e a maior parte das respostas para certeza foram assinaladas nos pontos positivos da escala, com uma concentração nos pontos mais extremos da escala ( 2 e 3 , negativos para dúvida 2 e positivos para a certeza).

$\mathrm{Na}$ análise estatística, realizamos uma comparação entre os resultados esperados para as atitudes de certeza ( 2 e 3) e dúvida 2 (-2 e -3). No teste de 
proporção encontramos p=0,000 nas duas atitudes. É importante ressaltar que, nesse teste, a hipótese era a de que a proporção esperada era maior do que a proporção não esperada. Isso mostra que os participantes do teste perceptivo não apenas perceberam qual o lado da escala assinalar, mas colocaram as respostas nos locais que representavam uma expressão inequívoca daquela atitude para os falantes do GC.

O resultado da dúvida 1 foi bem diferente (gráfico 1). Inicialmente, vemos que não há nenhuma resposta em -3 e 3 . Em seguida, começam a aparecer mais respostas em - 2 e 2 para culminar em um pico de respostas em -1 e 1, diminuindo novamente ao chegar no ponto 0 da escala (gráfico 1). Ao realizarmos a análise estatística de teste de proporção, p foi igual a 1, ou seja, o resultado esperado não é maior do que o esperado.

Essa análise da dúvida 1 mostra que não só a expressão da dúvida 1 não foi tida como uma expressão nítida de dúvida, como ultrapassou claramente o limite da neutralidade indo em direção aos pontos positivos da escala. Porém, com poucas respostas em 2. Perguntamo-nos, então, qual seria a interpretação pragmática para tal fenômeno.

Se trouxermos para esta discussão três pontos-chave deste estudo, podemos chegar a uma proposta diferente da apresentada até aqui para a chamada dúvida 1. Os três pontos são: a. um menor número de participantes utilizou o padrão geral encontrado na dúvida 1; b. os resultados do estudo da produção apresentados aqui (diferenciando claramente dúvida 1 e 2), e c. os resultados do teste perceptivo apresentados acima.

Vemos que o comportamento das duas formas de dúvida aqui apresentadas se diferenciam nos três pontos descritos no parágrafo anterior. Além disso, podemos verificar que a forma mais escolhida para a produção da dúvida, a dúvida 2, foi a que obteve escores mais negativos na escala do teste perceptivo. Com isso, podemos inferir que, neste estudo, a forma analisada como dúvida 2 representa realmente a expressão da atitude de dúvida. E qual seria a implicação pragmática desse fato para a dúvida 1?

Uma hipótese que levantamos aqui é que a expressão da dúvida 1 não seria uma expressão de dúvida de fato e sim de atitude de incerteza, uma vez que foi relativamente pouco produzida ao solicitarmos expressão de dúvida e obteve os resultados acima apresentados no teste perceptivo (com pontuação positiva e negativa). Acreditamos, no entanto, que tal questão deva ser mais explorada em estudos posteriores. 


\section{Respostas do teste perceptivo para o GE}

Passemos agora para exposição e análise dos resultados do teste perceptivo para os enunciados de indivíduos com gagueira. Os resultados do teste perceptivo para o GE (1 e 2) na comparação entre o que era esperado e o que não era esperado são mostrados na tabela 1, com dois resultados de p. O primeiro, se o resultado dos valores que eram esperados são diferentes do restante, e o segundo, se eram maiores do que o restante. A tabela 2 mostra os resultados do teste estatístico de duas proporções na comparação dentro de cada grupo de pessoas com gagueira a partir da pergunta: cada resposta encontrada na escala é diferente ao comparar a certeza e a dúvida? As porcentagens das respostas do teste perceptivo para fala dos grupos com gagueira encontram-se nos gráficos 2 e 3.

\section{Tabela 1 - Teste de uma proporção $(p<0,05)$ para as atitudes do GE ( 1 e 2) do teste perceptivo.}

\begin{tabular}{l|c|c|c}
\hline \multicolumn{1}{c}{ Grupo } & \multicolumn{2}{c}{ Atitude } & Dalor de p \\
\hline \hline GE1 & Certeza & $0,000^{*}$ & 1 \\
\hline & Dúvida & $0,000^{*}$ & 1 \\
\hline GE2 & Certeza & $0,000^{*}$ & 1 \\
\hline & Dúvida & $0,000^{*}$ & 1 \\
\hline \hline
\end{tabular}

Fonte: Elaboração própria.

Tabela 2 - Teste de duas proporções $(p<0,05)$ comparando certeza e dúvida na escala do teste perceptivo para GE1 e GE2.

\begin{tabular}{lccccccc}
\hline Grupos & & \multicolumn{5}{c}{ Escala } & \\
& -3 & -2 & -1 & 0 & 1 & 2 & 3 \\
\hline \hline GE1 & 1 & 0,2 & 0,5 & 0,06 & 0,9 & 0,6 & 1 \\
GE2 & 0,5 & 0,7 & $0,001^{*}$ & 0,06 & 0,7 & $0,001^{*}$ & $0,007^{*}$ \\
\hline \hline
\end{tabular}

Fonte: Elaboração própria. 


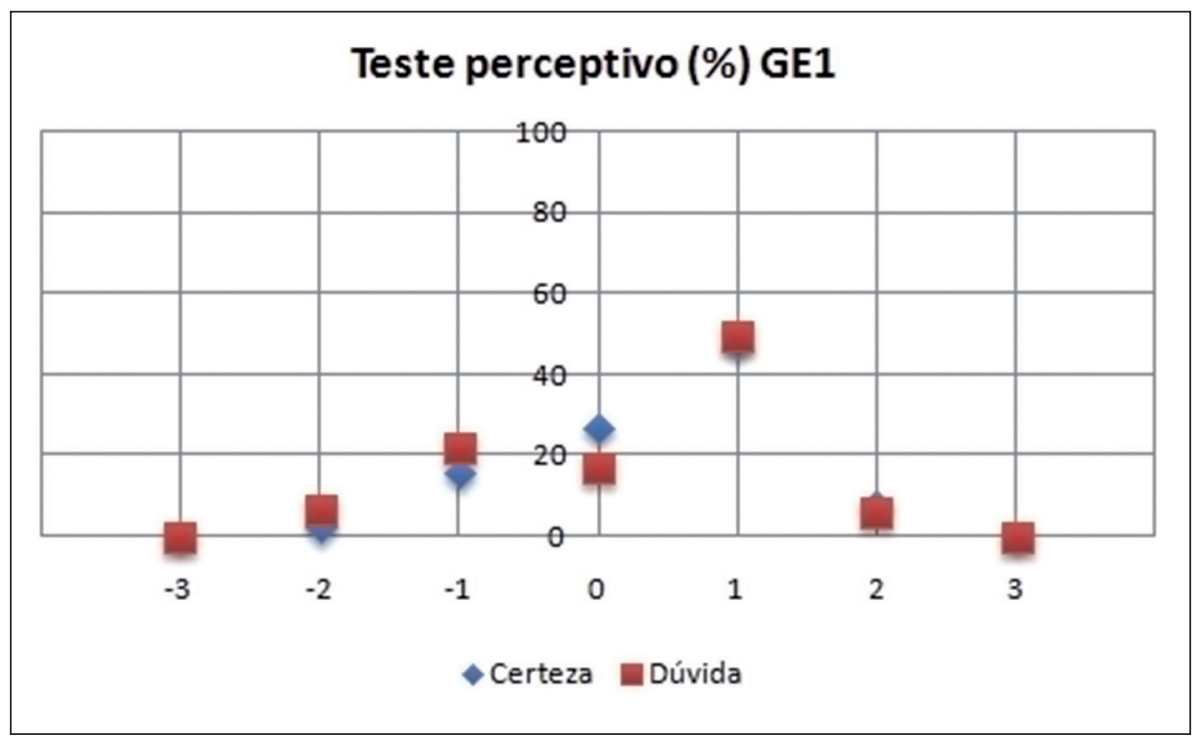

Fonte: Elaboração própria.

O primeiro aspecto relevante do gráfico acima a ser destacado é que quase não há diferença entre a certeza e a dúvida no teste perceptivo de GE1, sem diferença estatisticamente significativa (tabela 2). Ou seja, apesar de serem atitudes opostas, tendo como base a escala apresentada, ao ouvir os dois tipos de enunciado, os participantes tiveram, em geral, uma impressão semelhante. É possível observar, para GE1, um fator que atrai atenção: as extremidades da escala (-3 e 3) não foram assinaladas. Não só os extremos não foram assinalados, como o número logo seguido desses, o 2 (+ ou -) foi assinalado poucas vezes pelos participantes do teste perceptivo. A concentração de respostas do teste perceptivo ( $90 \%$ das respostas) ficou entre $-1 \mathrm{e}+1$.

A tabela 2 mostra que, apesar do resultado esperado ser diferente do resultado não esperado tanto para certeza quanto para dúvida, o primeiro não é estatisticamente maior que o segundo. Pelo contrário, é bem menor.

Esses resultados mostram uma clara dificuldade de percepção das atitudes expressas por parte dos indivíduos que ouviram os enunciados de GE1. O gráfico 3 mostra os resultados de GE2. 


\section{Gráfico 3 - Resultado em porcentagem do teste perceptivo para o GE2.}

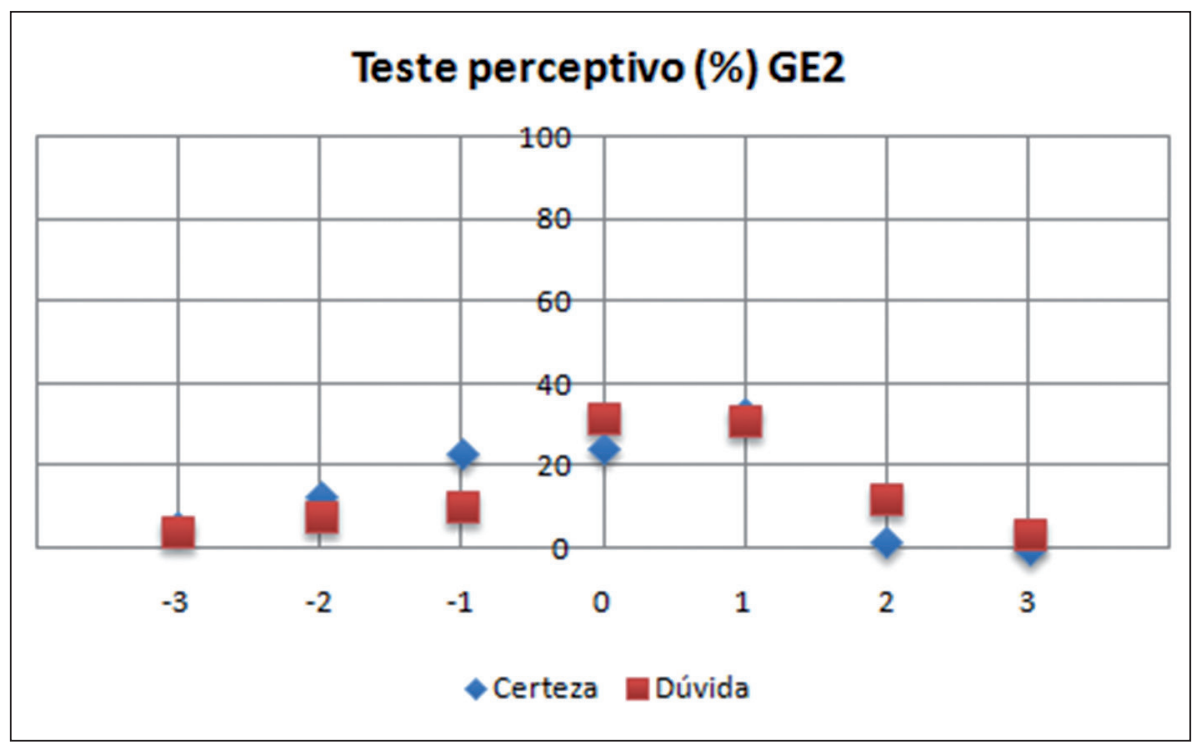

Fonte: Elaboração própria.

Apesar de apresentar respostas um pouco mais diferenciadas do que aquelas dos enunciados de GE1, os resultados do teste perceptivo para GE2 mostram que as respostas de certeza e dúvida também estão muito próximas. Tal fato indica que os indivíduos que ouviram os enunciados de GE2 não conseguiram diferenciar as atitudes de certeza e dúvida, mantendo o padrão observado para GE1: extremidades (-3, -2, 2 e 3) pouco assinaladas, com consequente concentração de respostas no meio da escala (81\% das respostas entre -1 e 1), sem diferenças importantes entre certeza e dúvida.

As diferenças estatisticamente significativas encontradas na diferenciação entre certeza e dúvida para GE2 são nos pontos -1, 2 e 3 da escala. Porém, quando examinamos o gráfico 3, vemos que no ponto -1 (parte da escala direcionada para dúvida) há mais respostas de certeza. Já nos pontos 2 e 3 (parte da escala separada para certeza) há mais respostas de dúvida. Assim, há uma inversão entre a atitude que a pessoa desejava expressar e a atitude percebida pelo ouvinte.

\section{Comparação das respostas do teste perceptivo entre GC, GE1 e GE2}

A partir do visto para GC, GE1 e GE2, vemos que há uma diferença importante entre esses grupos: há diferença e adequação de respostas relevantes na diferenciação das atitudes de certeza e dúvida apenas no GC. 
Tal fato fica ainda mais claro ao compararmos os resultados por atitude nos três grupos, como mostram a tabela 3 e os gráficos 4 e 5. Na comparação da atitude de dúvida tivemos um impasse: o GC apresentou duas formas de produzir a expressão de dúvida, sendo uma mais próxima à modalidade declarativa e outra mais próxima à modalidade interrogativa. Tal diferenciação não ocorreu no GE. Poderíamos optar por uma forma ou outra para comparação dos dados, mas qual seria a melhor escolha? Provavelmente a forma que chamamos de dúvida 1 seja a mais adequada, uma vez que essa se assemelha à forma declarativa, assim como os enunciados expressando dúvida produzidos pelo GE. Porém, essa suposição não foi testada. Dessa maneira, optamos por apresentar a comparação das duas formas de expressão de dúvida do GC com o GE, apresentados na tabela 3.

\section{Tabela 3 - Teste de duas proporções $(p<0,05)$ comparando os grupos em cada ponto da escala do teste perceptivo por atitude.}

Atitudes Grupos Escala

\begin{tabular}{|c|c|c|c|c|c|c|c|c|}
\hline & & -3 & -2 & -1 & 0 & 1 & 2 & 3 \\
\hline & GC X GE1 & 1 & 0,08 & $0,000^{*}$ & $0,03^{*}$ & $0,000^{*}$ & $0,000^{*}$ & $0,000^{*}$ \\
\hline \multirow[t]{3}{*}{ Certeza } & GC X GE2 & $0,000^{*}$ & $0,000^{*}$ & $0,000^{*}$ & $0,03 *$ & $0,000^{*}$ & $0,000^{*}$ & $0,000^{*}$ \\
\hline & GE1 X GE2 & $0,01^{*}$ & $0,001^{*}$ & 0,08 & 0,6 & $0,008 *$ & $0,01^{*}$ & 1 \\
\hline & GC X GE1 & 1 & 0,9 & $0,008^{*}$ & $0,000^{*}$ & $0,000^{*}$ & 0,2 & 1 \\
\hline \multirow[t]{2}{*}{ Dúvida 1} & GC X GE2 & $0,000^{*}$ & 0,7 & 0,7 & $0,000^{*}$ & $0,000^{*}$ & $0,000^{*}$ & $0,001^{*}$ \\
\hline & GE1 X GE2 & $0,03^{*}$ & 0,7 & $0,006^{*}$ & $0,001^{*}$ & $0,001^{*}$ & $0,04^{*}$ & 0,06 \\
\hline \multirow[t]{2}{*}{ Dúvida 2} & GC X GE1 & $0,000^{*}$ & $0,000^{*}$ & $0,000^{*}$ & $0,000^{*}$ & $0,000^{*}$ & $0,000^{*}$ & 1 \\
\hline & GC X GE2 & 0,000 * & $0,000 *$ & $0,001^{*}$ & $0,000^{*}$ & $0,000^{*}$ & 0,000 * & $0,001^{*}$ \\
\hline
\end{tabular}

Fonte: Elaboração própria. 


\section{Gráfico 4 - Resultado em porcentagem do teste perceptivo para a atitude de certeza contrapondo GC, GE1 e GE2.}

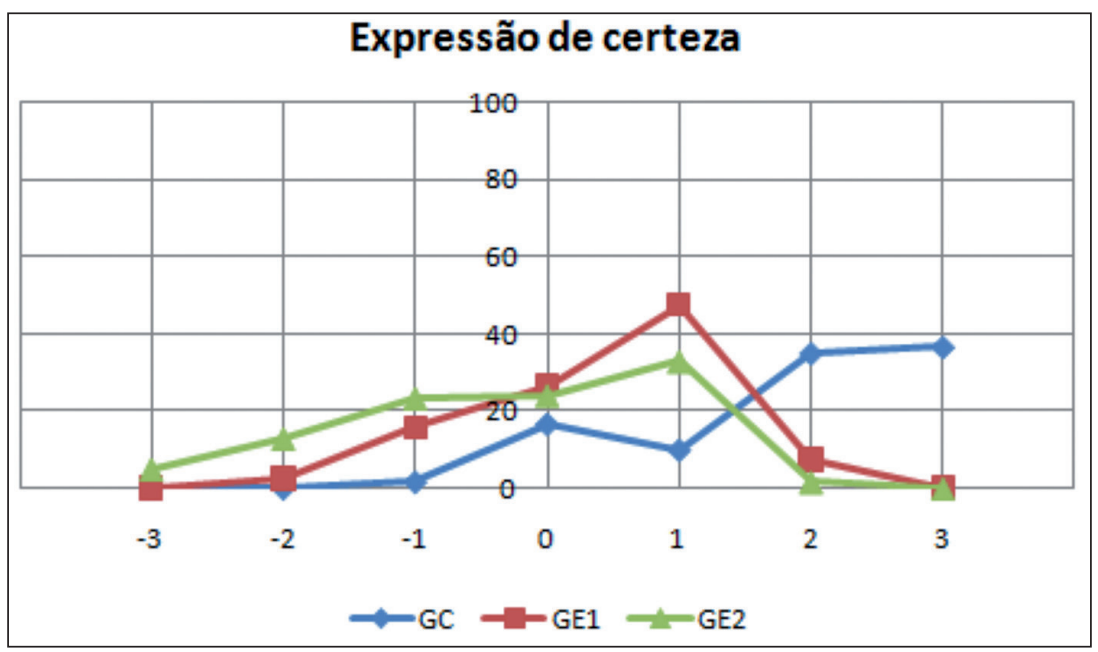

Fonte: Elaboração própria.

A análise da expressão de certeza pode ser realizada dividindo-se o gráfico 4 em 3 partes (parte esquerda, central e direita). A primeira, relativa à parte esquerda do gráfico, apresenta os valores negativos (de -3 a -1). Como estamos tratando da expressão de certeza, os valores negativos são o extremo oposto do que esperamos como resultado. Enquanto os participantes do teste perceptivo não assinalaram nenhuma vez os extremos negativos (-3 e -2) e praticamente nenhuma vez o -1 para o GC, esses escores foram dados ao GE. Ressalta-se que o GE2 obteve mais pontos negativos do que GE1. Essa primeira observação mostra que ao tentar expressar certeza, o GE (1 e, principalmente, o 2) foi interpretado em alguns momentos como expressando dúvida.

A segunda parte do gráfico 4 a ser discutida aqui é o ponto zero da escala. É interessante observar que os resultados foram próximos para GE1 e GE2, com $27 \%$ e $24 \%$, respectivamente, sem diferenças estatisticamente significativas. Tanto GE1 quanto GE2 apresentam diferença estatisticamente quando comparados ao GC, sendo que o último obteve apenas 16\% das respostas no ponto zero.

Por fim, a terceira parte do gráfico 4 que discutiremos é a parte positiva da escala (quanto mais positiva, mais representa a expressão da certeza). É possível verificar que tanto GE1 quanto GE2 apresentam o pico das respostas no valor 1 da escala, obviamente o mais próximo do neutro. Porém GE2 apresenta menos respostas do que GE1, com diferença estatisticamente significativa. Já GC 
apresenta muitas respostas nos valores 2 e 3 , enquanto nenhum participante do teste perceptivo assinalou o valor 3 positivo para expressão de certeza do GE1 e GE2, com diferença estatisticamente significativa.

Para discutir a expressão de dúvida comparando GC, GE1 e GE2, temos que escolher entre a comparação com dúvida 1 ou dúvida 2, do GC. Ambas parecem opções viáveis: a dúvida 1 se sobrepõe-se à modalidade declarativa em GC como a dúvida em GE1 e GE2, porém a dúvida 2 foi realizada por 9 dos 12 participantes do GC, sendo o tipo eleito naturalmente pelos falantes desse grupo como a forma principal. Colocamos, então, as duas formas no gráfico 5 para fins comparativos.

\section{Gráfico 5 - Resultado em porcentagem do teste perceptivo para a atitude de dúvida contrapondo GC, GE1 e GE2.}

\section{Expressão de dúvida}

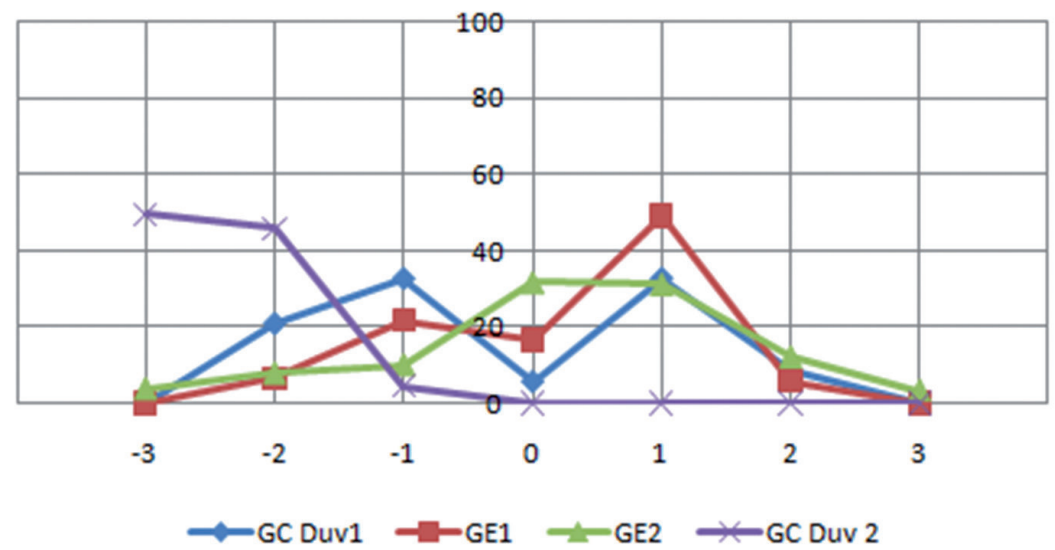

Fonte: Elaboração própria.

Vemos que a expressão de dúvida 1 do GC apresenta resultados mais próximos entre os grupos, destacando-se alguns pontos:

- Primeiro, as pontas da escala, que representariam as atitudes entendidas pelo interlocutor como uma expressão clara da dúvida ou certeza, -3 e 3 respectivamente, praticamente não são assinaladas para os enunciados de dúvida de GC e GE1, sem diferença estatisticamente significativa (não estamos discutindo neste momento dúvida 2 do GC).

- Segundo, do lado positivo da escala, mais próximo da certeza, o número 2 apresenta uma porcentagem bem baixa, sem diferença estatisticamente significativa entre GE1 e GC. 
No entanto, vemos uma clara diferença na tipologia das curvas do gráfico 5, considerando a parte mais assinalada no teste perceptivo (de -1 a 1): GC apresenta um pico em -1, uma queda brusca no zero (neutro) e um outro pico em +1, enquanto GE1 e GE2 apresentam um platô e um vale (sendo que GE2 apresenta valor baixo em -1, sobe para zero e se mantém até +1 enquanto GE1 inicia mais baixo, se mantém mais baixo (até 0) e depois tem um pico em +1 ), com diferenças estatisticamente significativas entre os grupos.

Já ao comparar a dúvida 2 do GC e a dúvida do GE1 e GE2, vemos resultados muito distantes, com o maior número de respostas do GC sendo -2 e -3 , números praticamente não marcados na escala para GE1 e GE2, com diferenças estatisticamente significativas.

\section{Conclusão}

A hipótese da presente pesquisa, confirmada pelo nosso estudo, partiu do pressuposto de que todos os participantes tiveram a intenção de produzir as atitudes solicitadas, seja de certeza, seja de dúvida: apesar de todos assumirem a mesma posição inicial de intenção de expressão de atitude, os indivíduos que não apresentam gagueira têm êxito na comunicação linguística dessas atitudes, enquanto indivíduos gagos falham na comunicação linguística dessas atitudes.

Essa hipótese foi examinada por meio de um teste perceptivo, no qual os ouvintes marcaram respostas em uma escala de -3 (dúvida) a 3 (certeza), passando pelo zero (neutro). Os resultados confirmaram essa hipótese, uma vez que o índice de reconhecimento das atitudes de certeza e dúvida do GC foi muito maior do que de GE1 e de GE2. Um resultado interessante a ser observado quanto ao teste perceptivo do GE é que os ouvintes não diferenciaram bem quais eram os enunciados de dúvida e certeza, confundindo-os.

Em suma, a partir de uma mesma intenção comunicativa, a expressão de certeza ou de dúvida, os participantes do GC reorganizaram os parâmetros prosódicos de tal forma que foi possível para os ouvintes que participaram do teste perceptivo perceber a atitude programada. Já para o GE, apesar de ter a mesma intenção, a reorganização prosódica realizada não foi suficiente para que o interlocutor diferenciasse as atitudes com base exclusivamente nos parâmetros prosódicos.

\section{Agradecimentos}

Agradecemos a CAPES por financiar parte deste estudo. 
CELESTE, L. C; REIS, C. Attitudes expression on stuttering speech: Perception of fluent speakers. Alfa, São Paulo, v.57, n.1, p.275-293, 2013.

- ABSTRACT: The purpose of this study is to verify how fluent speakers of Brazilian Portuguese perceive the expression of certainty and doubt attitudes on stutterers' speech. For such, data was collected in two moments: 1. speech material; and 2. perceptive test. Two groups participated in the first moment: 12 stuttering people ( $E G)$ and 12 non-stuttering people (CG). These participants recorded two utterances in each of the three forms studied (neutral, certainty and doubt). For the perceptive test, 60 judges have participated: 30 judged CG'S utterances and 30 judged EG's utterances. 1,440 responses were recorded for CG and 1,080 for $E G$. The statistical test of an affirmative over one and two proportions was used, with 95\% significance. The results showed a statistically significant difference between the results of CG and EG judges: judges recognize attitudes expressed by non-stuttering people better than those expressed by stuttering ones.

- KEYWORDS: Perceptive test. Prosody. Attitude. Stuttering.

\section{REFERÊNCIAS}

ANDRADE, C. R. F. Gagueiras infantis: diagnóstico e intervenção precoces. Carapicuíba: Pró-Fono, 1999.

ARCURI, C. F. et al. Speech rate according to stuttering severity. Pró-Fono Revista de Atualização Científica, Barueri, v.21, n.1, p.45-50, 2009. Título original: Taxa de elocução de fala segundo a gravidade da gagueira.

Medidas acústicas de duração no reconto de histórias em indivíduos gagos. ACTA ORL/Técnicas em Otorrinolaringologia, São Paulo, v.24, n.3, p.113116, 2006.

BOSSHARDT, H. G. et al. Spontaneous imtation of fundamental frequency and speech rate by nonstutters and stutters. Journal of Psycholinguistic Research, New York, v.26, n.4, p.425-448, 1997.

CAMPBELL, J. H.; HILL, D. G. Systematic disfluency analysis. Evanston: Northwestern University and Stuttering Foundation of America, 1995.

CARDOSO, B.; REIS, C. Variables for the study of the temporal organization in speech disorders. In: CONGRESSO SPEECH PROSODY, 4., 2008, Campinas. Anais... Campinas: RG/CNPq, 2008. p.195-198.

JAKUBOVICZ, R. Gagueira: diagnóstico e tratamento. Rio de Janeiro: Revinter, 1997.

MARTINS, V. de O.; ANDRADE, C. R. F. de. Perfil evolutivo da fluência da fala de falantes do Português brasileiro. Pró-Fono Revista de Atualização Científica, Barueri, v.20, n.2, p.7-12, 2008. 
PAVEAU, M.; SARFATI, G. As grandes teorias da linguística: da gramática comparada à pragmática. Tradução de Maria Rosário Gregolin et al. São Carlos, SP: Clara Luz, 2006.

SOARES, E. Q. W. Aspectos prosódicos da fala na gagueira infantil. 2004. $151 \mathrm{f}$. Dissertação (Mestrado em Linguística) - Faculdade de Letras, Universidade Federal de Minas Gerais, Belo Horizonte, 2004.

SPERBER, D.; WILSON, D. Relevance: communication e cognition. Cambridge: University of Cambridge, 1995.

TRIOLA, M. F. Introdução à Estatística. 9.ed. Rio de Janeiro: LTC, 2005.

WILSON, D.; WHARTON, T. Relevance and prosody. Journal of Pragmatics, Amsterdam, v.38, p.1559-1579, 2006.

YAIRI, E.; AMBROSE, N. G. Early chilhood stuttering I: persistency and recovery rates. Journal of Speech, Language, and Hearing Research, Rockville, v.42, p.10971112, out. 1999.

Recebido em 14 de abril de 2011

Aprovado em 24 de novembro de 2012 
